\title{
Acceptability and predictors of uptake of anti-retroviral pre-exposure prophylaxis (PrEP) among fishing communities in Uganda: A cross-sectional discrete choice experiment survey
}

Monica O Kuteesa ${ }^{1,2}$, Mathew Quaife ${ }^{2}$, Sam Biraro ${ }^{3}$, Kenneth R Katumba ${ }^{1}$, Janet Seeley ${ }^{1,2}$ Anatoli Kamali ${ }^{4}$, Damalie Nakanjako ${ }^{5,6}$

1. MRC/UVRI and LSHTM Uganda Research Unit, Entebbe, Uganda

2. London School of Hygiene and Tropical Medicine, London, UK

3. ICAP, Columbia University, Mailman School of Public Health, New York, USA

4. International AIDS Vaccine Initiative, Nairobi, Kenya

5. Department of Internal Medicine, Makerere University, Kampala

6. Infectious Diseases Institute, Kampala, Uganda

\section{ABSTRACT}

We used a discrete choice experiment to assess the acceptability and potential uptake of HIV pre-exposure prophylaxis (PrEP) among 713 HIV-negative members of fishing communities in Uganda. Participants were asked to choose between oral pill, injection, implant, condoms, vaginal ring (women), and men circumcision. Product attributes were HIV prevention effectiveness, sexually transmitted infection (STI) prevention, contraception, waiting time, and secrecy of use. Data were analysed using mixed multinomial logit and latent class models. HIV prevention effectiveness was viewed as the most important attribute. Both genders preferred oral PrEP. Women least preferred the vaginal ring and men the implant. Condom use was predicted to decrease by one third among men, and not to change amongst women. Oral PrEP and other new prevention technologies are acceptable among fishing communities and may have substantial demand. Future work should explore utility of multiple product technologies that combine contraception with HIV and other STI prevention. 


\section{Key words}

Fisherfolk, HIV prevention, discrete choice experiment, pre-exposure prophylaxis, Uganda 


\section{Aceptabilidad y productores de la captación de antirretrovirales antes de la exposición. Profilaxis entre las comunidades de pescadores en Uganda: un corte transversal Encuesta de experimento de elección discreta.}

Utilizamos un experimento de elección discreta para evaluar la aceptabilidad y la aceptación potencial. Profilaxis de pre exposición al VIH entre 713 miembros de la comunidad de Pescadores que no tienen VIH. en Uganda. Se pidió a los participantes que eligieran entre la píldora oral y la inyección, Implantes, condones, anillos de vagina, y para circuncisión masculina. Atributos del product fueron efectividad en la prevención del VIH, prevención de infecciones de transmisión sexual, anticoncepción, tiempo de espera y secreto de uso. Los datos fueron analizados utilizando mixtos. Lógica y modelos de clase latente. La efectividad la prevención del VIH fue vista como el atributo más importante. Ambos géneros prefirieron la preparación oral/ píldora, las mujeres menos prefirió el anillo de vagina y los hombres el implante. Se predijo que el condón disminuiría en un tercio entre los hombres y no cambiaria entre las mujeres. La comunidad de pescadores acepta la preparación oral / píldora y otras tecnologías de prevención. y puede tener una demanda sustancial. El plan futuro debe explorar la utilidad de las tecnologías de múltiples productos que combinan la anticoncepción con el VIH y otras medidas de prevención de ITS. Palabras clave. personas más frescas, prevención del VIH, experimento de elección discreta, profilaxis previa a la exposición, Uganda. 


\section{INTRODUCTION}

Although new HIV infections in Eastern and Southern Africa declined by 30 between 2010 and 2017, the region still accounts for $43 \%$ of new HIV infections globally(1). Fishing communities constitute about $10 \%$ of Uganda's population and are one of the key populations at high risk of HIV-infection in Uganda (2-5). HIV prevalence among fishing communities is estimated to be five times the national average, with women disproportionately affected (2-4, 6-8). HIV incidence among fishing communities is estimated to be between 3.3 to 6.7 cases/100 person-years, compared to $<1$ cases/100 person years at national level $(3,4,9)$. This picture is mirrored in fishing communities elsewhere in sub-Saharan Africa (10).

Fishing communities have increased susceptibility to HIV and other sexually transmitted infections (STI) due to complex and interacting factors including alcohol misuse and illicit drug use $(2,11-13)$, poor access to healthcare including HIV prevention and care services and transactional sex $(4,10,14)$. High mobility in search for better fish yields and market for fish is a crucial livelihood strategy for fishing communities (15-17). However, high mobility comes with prolonged separation from family and high risk bahaviour both major risk factors for HIV acquisition and transmission. Similarly, cultural norms of hyper-asculinity, peer pressure, low perception of risk to HIV and the low socioeconomic and cultural status of women have been highlighted as drivers of the epidemic in fishing communities $(3,4,8,14,18,19)$.

Novel prevention approaches are required to complement existing HIV prevention strategies to further reduce HIV incidence among fisher folk. A number of recently developed antiretroviral (ARV)-based HIV prevention modalities are considered in this study. Oral PrEP is recommended for use in Uganda and elsewhere (20-27), whilst the efficacy of intra-vaginal rings $(28,29)$, and microbicide gels $(30)$ in reducing HIV risk has been shown in clinical trials. Long-acting injectable PrEP is undergoing phase 3 clinical trials (31) to assess efficacy, effectiveness and safety of patients. Implants are 
also a viable options for HIV prevention, whilst male circumcision has been shown to reduce HIV risk by up to $60 \%(32,33)$. New HIV prevention products may increase population protection to HIV because they allow users to exercise choice of the most suitable HIV prevention method at the time they need it. Multipurpose HIV prevention technologies (MPTs) which provide users with more options for contraception and STI prevention prevent users from one or more of unintended pregnancy, HIV and STI are considered potentially attractive to reduce the health burden associated with HIV, STI and unintended pregnancies. Previous work has estimated MPTs to be potentially costeffective in high HIV incidence groups $(37,38)$.

Guidelines for oral PrEP implementation for key populations have been published by the Centers for Disease Control and Prevention and the World Health Organization $(34,35)$. In addition, PrEP acceptability studies and demonstration projects have been widely conducted in other key populations such as female sex workers, men who have sex with men, serodiscordant couples, transgender, and intravenous drug users $(30,36-41)$. However, these PrEP guidelines and demonstration studies do not address the special needs of fishing communities such as their high mobility and low perception of risk to HIV (42), which might have implications for PrEP service delivery and uptake. This is largely due to insufficient evidence at a micro-level, in local country and community contexts. Moreover fisher folk have extensive sexual networks which bridge into the general population $(18,43)$.

Prior to roll-out of oral PrEP and other new HIV prevention products as part of the HIV combination prevention package for fishing communities, formative studies on acceptability are required. To obtain reliable estimates of preferences and predictions of uptake of different forms of PrEP, we used a discrete choice experiment (DCE) methodology. DCEs ask respondents to make a number of choices between hypothetical HIV prevention options and allow us to evaluate the respondents' preferences towards existing and possible future HIV prevention methods (44). Our study explored the effect 
of product characteristics on preferences for five products (oral PrEP, vaginal ring, implant, injectable long-acting PrEP, male circumcision, male condom) to identify potential tradeoffs and predict uptake of products. The DCE was implemented within a cross-sectional survey in a stratified random sample of fishing communities around Lake Victoria.

\section{METHODS}

\section{Study design and setting}

We conducted a cross sectional survey between December 2016 and March 2017 in four fishing communities around the shores of Lake Victoria (two rural, two urban) in the districts of Mpigi, Wakiso, and Kampala. The survey was nested in an HIV-combination prevention cluster randomized pilot study (HIVCOMB) conducted by the MRC/UVRI Uganda Research Unit on AIDS (45). Under the HIVCOMB study, in the year prior to DCE study, study communities received HIV prevention packages including male circumcision, male condoms, HIV testing, and behavior change communication.

\section{Discrete choice experiment}

Four months prior to the survey, we carried out formative research using qualitative methods to identify attributes and attribute levels. Attributes are the important characteristics of different choices. For example, one attribute could be HIV prevention effectiveness with attribute levels being $55 \%, 75 \%$, or $95 \%$ (Table 1 ). 
Table 1: DCE attributes and levels

\begin{tabular}{|l|l|}
\hline Product & $\begin{array}{l}\text { Oral PrEP, Vaginal ring, Implant, Injectable PrEP, Male } \\
\text { Circumcision } \\
\text { Opt out alternative: No product/condom }\end{array}$ \\
\hline HIV protection & $55 \%, 75 \%, 95 \%$ \\
\hline STI protection & Yes, No \\
\hline Contraception & Yes, No \\
\hline Ability to use in & Yes, No \\
secret $\neq$ & \\
\hline $\begin{array}{l}\text { Waiting time * } \\
\text { * Waiting time was explained as including time to accessing product to using the product. This includes travel time and clinic waiting } \\
\text { time. } \\
\text { ₹ Secrecy was defined as the ability for an individual to use a product without their sexual partners' knowledge. }\end{array}$
\end{tabular}

This included a scoping review; 15 in-depth interviews with 8 men and 7 women; and 12 focus group discussions (FGDs) (6 with men, 6 with women); 2 with HIV-infected persons, 10 with HIV negative persons; using semi-structured interview guides or open discussions. We conducted FGDs with HIV-infected persons to enrich the discussions on antiretroviral-based HIV prevention methods, in particular oral PrEP, given their experience of chronic medication. DCE tasks presented participants with choices between alternatives which were defined by the defined attributes. To refine and validate the attributes and attribute levels, we conducted two workshops with a sub-sample $(n=40)$ of the FGD and in-depth interview respondents. All respondents were aged 18 and over. To improve the accuracy, validity, credibility, and applicability of the final list of potential attributes and attribute levels, we used member checking and ranking exercises. The DCE had five attributes: HIV protection (effectiveness), STI protection, contraception, ability to use in secret, and waiting time. Waiting time included time to access and use the product including travel time and clinic waiting time. The product attributes and attribute levels of the final DCE were as shown in Table 1. Figure 1 gives an example of DCE tasks, as presented to respondents. The DCE was piloted among 10 
people, with data analysed to generate a D-efficient statistical design for the final set of tasks in NGENE software (46). The final design incorporated ten choice tasks and participants were shown two new products and the option to opt-out. The opt-out alternative was a male condom for those who reported using a condom at last sex and no product for those who did not, thereby allowing more realistic uptake prediction (51).

To inform respondents' choice of potentially unfamiliar products, interviewers gave participants sample products with no active ingredient, showed respondents pictures of products on the computer tablet, and explained how each of the products was to be used.

\section{Figure 1: Example DCE task}

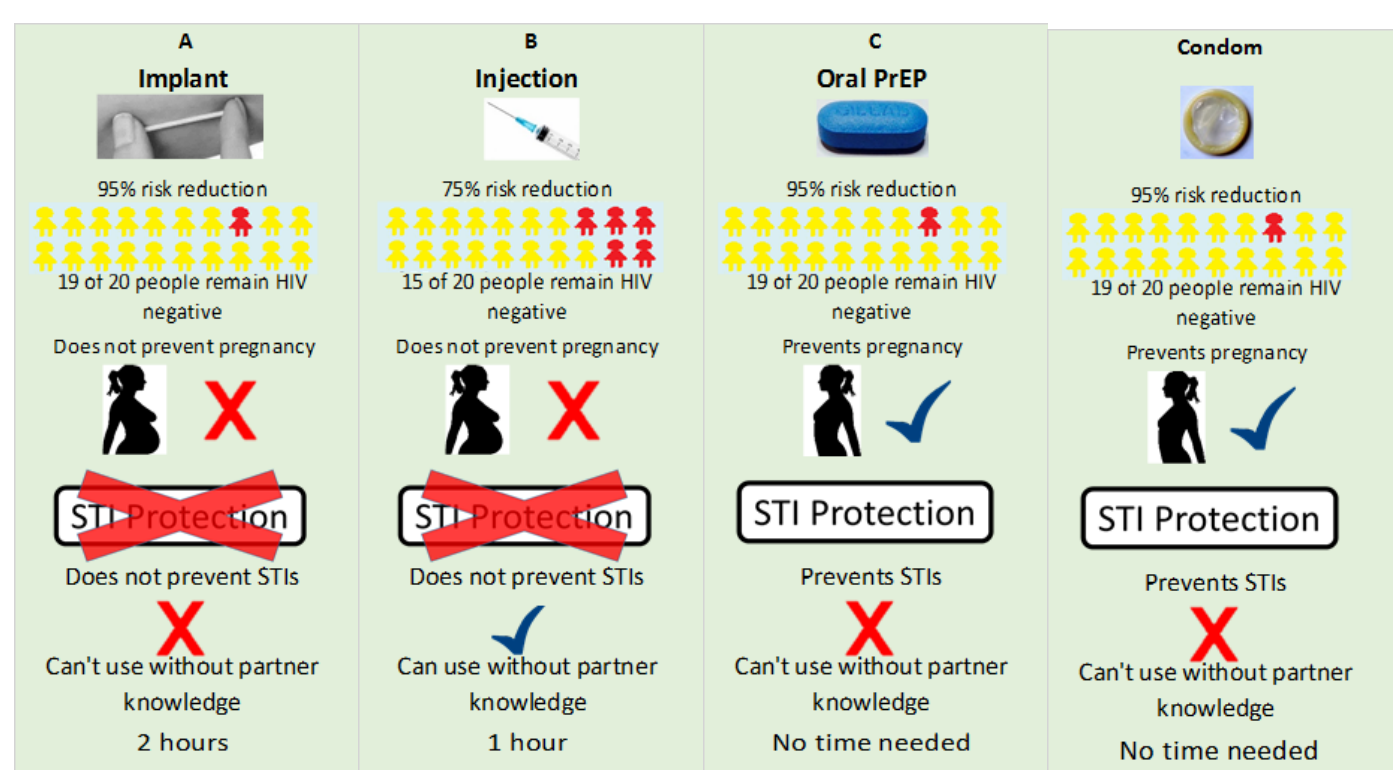

\section{Survey}

\section{Sample size and sampling}

We used a sampling frame from a previous study conducted in 2014-2015.A mapping and census exercise was done in each of the four communities. In each community, the census population was stratified into the six strata consisting of combinations of gender (male, female) and age (18-24 years, 24-34 years and 35 years or older), to ensure representation of gender and age groups. Participants' HIV status was determined to 
ensure approximately 200 HIV un-infected were included. The sampling fractions differed between strata to allow oversampling of HIV-uninfected respondents. The sampling fractions were chosen based on the HIV prevalence in previous literature (7). Respondents who were absent after three visits over a three-month period were replaced at random by respondents from the same fishing community, matched for age group, gender and HIVnegative status. We replaced 87 missing respondents with respondents from the sample, matched for age, gender and HIV status, and realized a final sample size of 805 .

\section{Respondent selection at household level}

Inclusion criteria were residence in the fishing community for over three months, age 18 years and older, and consent to participate in the study. To prevent involuntary disclosure of HIV status, HIV positive respondents were included in the survey, however, data analyzed in this paper focused on HIV negative respondents only. During the study interviews, our team provided HIV testing to the wider community to enhance community engagement.

Adults were excluded if they did not understand the common dialects (English or Luganda) used by the research team. All eligible respondents in a sampled household were selected to make the study more acceptable to the community. Sample weights inversely proportional to the sampling probability of a respondent were calculated for each of the six strata according to the target sampling probabilities. The sample weights were constant across the four study communities.

\section{Survey procedures}

At the community hubs (focal points and facilities that are easily accessible to community residents for health information and survey activities), survey staff conducted face-to-face screening of respondents for eligibility. Eligible respondents received pre-test counselling, HIV rapid testing and post-test counselling. We conducted face-to-face interviews in Luganda and collected data using android tablets running Open Data Kit software. The 
research team was gender-balanced and experienced in working with fishing communities. In addition to the DCE tasks the survey included questions on socio-demographics, sexual behaviors in the last three months, contraception, substance use, sexual violence, STIs, and HIV prevention.

\section{Laboratory measures}

We conducted rapid HIV tests at the community-hub using a pre-defined approved standard operating procedure and national testing algorithm. Alere Determine HIV $1 / 2$ whole blood assay (Alere medical, Chiba, Japan), STAT-PAK rapid test HIV 1/2 (Chembio diagnostic systems NewYork, U.S.A) and Unigold (Trinity Biotech, Wicklow, Ireland) HIV confirmatory tests were conducted in an accredited laboratory using ELISA HIV Murex Diasori: Ref 9E25-02 UK and BIOKIT Bio Elisa HIV1/2 Ag/Ab, SPAI. All recruits enrolled into the survey accepted HIV testing.

\section{Data management and analysis}

\section{DCE data}

We used a standard stated preference choice modelling approach, used extensively elsewhere in health, environmental, $(47,48)$ and transport economics $(49)$. To model choice data from the $D C E$, we assume that each individual $i(i=1, \ldots, N)$ makes choices such that they maximize utility over the four alternatives presented $(j=1,2,3,4)$. Their axiomatic utility function $U_{i j}$ is decomposed into an explainable systematic component $V_{i j}$ and a random component $\varepsilon_{i j}$, and we specify an indirect utility function for the utility of respondent $\mathrm{i}$ from choice $\mathrm{j}$ in choice set $\mathrm{c}$ as the linear combination of attributes and an error term:

$$
V_{i j c}=X_{i j c} \beta+\varepsilon_{i j c}
$$


With $V_{i j c}$ the utility derived from a choice, $X_{i j c}^{\prime} \beta$ the component of utility that is captured by DCE attributes, and $\varepsilon_{i j c}$ a stochastic (random) component of utility. We specify the vector $X_{i j c}$ as the set of product attributes:

$$
X_{i j c} \beta_{j}=\beta_{0}+\beta_{1} \text { Product }_{j}+\beta_{2} \text { HIV }_{j}+\beta_{3} \text { Contraception }_{j}+\beta_{4} \text { STI }_{j}+\beta_{5} \text { Secret }_{j}+\beta_{6} \text { Time }_{j}
$$

Where Product $_{j}, \mathrm{HIV}_{j}$, Contraception $_{j}, \mathrm{STI}_{j}$, Secret $_{j}$, and Time $_{j}$ are the design attributes of the DCE, and $\beta_{0}$ a constant. We first estimate equation (1) using a multinomial (or conditional) logit model (MNL) which estimates the probability of individual $i$ choosing alternative $j$ among the set of options $\mathrm{c}$ as a probabilistic function of design attributes:

$$
P_{i j c}=\frac{\exp \left(X_{i j c} \beta\right)}{\sum_{J} \exp \left(X_{i j c} \beta\right)}
$$

The MNL model requires two restrictive assumptions: independence of irrelevant alternatives (IIA) and homogenous preferences across individuals, the latter assuming that every individual has the same tastes as the sample average (47). We assume that individuals choose the service associated with the highest utility such that the probability that individual $\mathrm{i}$ chooses alternative $\mathrm{j}$ over $\mathrm{k}$ is given as:

$$
\operatorname{Pr}_{j i}=\operatorname{Pr}\left(U_{j i}>U_{k i}\right)=\operatorname{Pr}\left(V_{j i}+\varepsilon_{j i}>V_{k i}+\varepsilon_{k i}\right)=\operatorname{Pr}\left(V_{j i}-V_{k i}>\varepsilon_{j i}-\varepsilon_{k i}\right)
$$


We take the standard approach to relaxing the IIA assumption and, as described by Hess et al. (49), estimate a mixed multinomial logit (MMNL) model where the parameter vector $\beta$ is assumed to be randomly distributed rather than fixed, such that $\beta \sim f(\beta, \Omega)$ :

$$
P_{n, i}=\int_{\beta} P_{n, i}\left(\beta, x_{n, i}\right) f(\beta, \Omega) d \beta
$$

Where $\Omega$ is a parameter vector of the distribution of the elements contained in $\beta$.

A restriction of the MMNL model is that the analyst needs to specify which parameters are randomly distributed across agents, as well as the way they are distributed (i.e. according to a normal, lognormal, or uniform distribution). The requirement of these assumptions is generally seen as a small cost for the ability of MMNL specifications to allow for taste heterogeneity, where preferences are allowed to vary across individuals $(47,49)$.

Finally, we explored preference heterogeneity through latent class modelling, which relaxes the IIA assumption across different groups of the sample. A latent class approach estimates separate parameter vectors for different classes of the sample with MNL models. The model relaxes the IIA assumption by assuming that preferences are homogenous within, but not across, classes. Thus the probability of respondent $i$ choosing alternative $j$ in choice set $c$ conditional on class membership $\mathrm{k}$ is:

$$
P_{i c}\left(J \mid \beta_{k}\right)=\sum_{k=1}^{K} \pi_{i k} \frac{\exp \left(X_{i j c} \beta_{k}\right)}{\sum_{J} \exp \left(X_{i j c} \beta_{k}\right)}
$$

The probability of respondent $\mathrm{i}$ belonging to class $\mathrm{k}$ is $\pi_{i k}$. Class membership is unobservable, however, we can regress the probability of class membership on a set of observable characteristics such that: 


$$
\pi_{i k}=\frac{\exp \left(Z_{i}^{\prime} \delta_{k}\right)}{\sum_{k=1}^{K} \exp \left(Z_{i}^{\prime} \delta_{k}\right)}
$$

(8)

$Z_{i}$ was the vector of individual characteristics, and $\delta_{k}$ was the vector of parameters for estimation. The number of classes was selected using Akaike Information Criteria (AIC) values and statistical inference of model results.

\section{Uptake predictions}

We use predicted probability analysis to simulate different scenarios of product uptake by substituting coefficients from the MNL model into equation 3, incorporating realistic product characteristics as follows. All new products were considered to be used in secret, whilst condoms were not, and efficacy assumptions were as follows: oral PrEP, injectable, implant $-61 \%(50)$, intravaginal ring - 56\%, for women aged 21 years and over (51), condom - 87\% (52), male circumcision - 67\% (53). Predictions were made among condom users and non-users, and among circumcised and non-circumcised men before a weighted average of overall coverage was generated. Although there have been concerns that the reliance of DCE data on stated preferences means that their predictive validity may be Iow, published studies show that DCEs can predict with reasonable accuracy (88\% specificity, 34\% sensitivity) (59).

\section{Ethics statement}

Ethical approval was obtained from the Uganda Virus Research Institute Research Ethics Committee, Uganda National Council for Science and Technology, and the University of Washington. The survey was conducted anonymously and written informed consent was obtained from all participants. 


\section{RESULTS}

\section{Sample characteristics}

We selected a sample of 1469 and reached 919 (63\%) respondents. We enrolled 805 respondents (55\%). Ninety-three participants had left the study area, nine were deceased, 12 refused to participate. Descriptive statistics are shown in table 2.

Table 2: Descriptive statistics

\begin{tabular}{|c|c|c|c|}
\hline & $\begin{array}{l}\text { Men } \\
n=412 \\
{[51 \%]}\end{array}$ & $\begin{array}{l}\text { Women } \\
n=393 \\
{[49 \%]}\end{array}$ & $\begin{array}{l}\text { Total } \\
805\end{array}$ \\
\hline \multicolumn{4}{|l|}{ Study sites } \\
\hline Ggaba & $89(22)$ & $95(24)$ & 184 \\
\hline Gerenge & $99(24)$ & $120(31)$ & 219 \\
\hline Ssenyondo & $124(30)$ & $112(28)$ & 236 \\
\hline Makungu & $55(13)$ & $29(7)$ & 84 \\
\hline Busimuzi & $45(11)$ & $37(9)$ & 82 \\
\hline \multicolumn{4}{|l|}{ Age group } \\
\hline $18-24$ years & 78 (19) & $93(24)$ & 171 \\
\hline $25-29$ years & $83(20)$ & $93(24)$ & 176 \\
\hline $30-34$ years & 76 (19) & $53(14)$ & 129 \\
\hline 35-39 years & $61(15)$ & 61 (16) & 122 \\
\hline $40-44$ years & $44(11)$ & $39(10)$ & 83 \\
\hline 45-49 years & $36(9)$ & $28(7)$ & 64 \\
\hline$\geq 50$ years & $34(8)$ & $26(7)$ & 60 \\
\hline Median age (IQR; years) & $32(18-78)$ & $30(18-81)$ & - \\
\hline Mean, SD & $34(11)$ & $32(11)$ & - \\
\hline
\end{tabular}




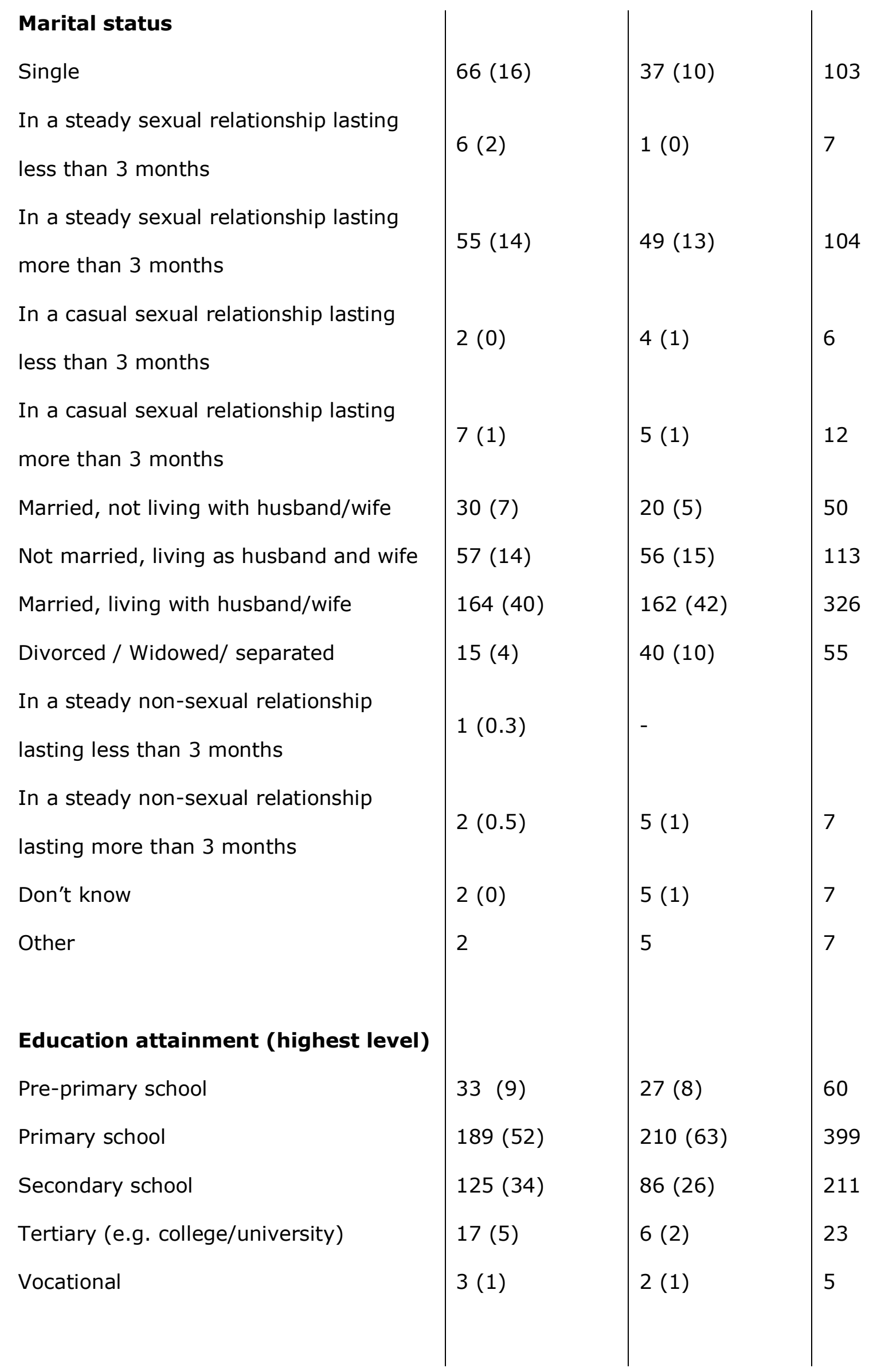




\begin{tabular}{|c|c|c|c|}
\hline \multicolumn{4}{|l|}{ Occupation } \\
\hline Fishing related activities & $147(36)$ & $49(13)$ & 196 \\
\hline Restaurant/bar & $1(0)$ & $50(13)$ & 51 \\
\hline Itinerary trade & $65(16)$ & $117(30)$ & 182 \\
\hline Farmer & $58(14)$ & $69(18)$ & 127 \\
\hline Housewife & - & $52(13)$ & 52 \\
\hline Student & $7(2)$ & $6(2)$ & 13 \\
\hline Elementary occupation & $128(31)$ & $44(11)$ & 172 \\
\hline Unemployed & $6(2)$ & $6(2)$ & 12 \\
\hline \multicolumn{4}{|l|}{ Age at first sex } \\
\hline$\leq 15$ years & $87(21)$ & $125(33)$ & 16 \\
\hline 16-18years & $182(45)$ & $201(52)$ & 577 \\
\hline$\geq 19$ years & $138(34)$ & $58(15)$ & 196 \\
\hline \multicolumn{4}{|l|}{ Male circumcision status } \\
\hline Yes & $241(59)$ & - & 241 \\
\hline No & $166(41)$ & - & 166 \\
\hline
\end{tabular}

\section{Discrete choice modelling}

Table 3 shows the MNL model and displays model coefficients (preference weights) for each attribute level alongside its standard error. Although DCE tasks were presented to all respondents regardless of HIV status, we only present results from HIV negative persons because they are a priority group for uptake of the HIV prevention products considered in this study. The standard distribution columns present the standard distributions of the random parameters, and where significant indicate statistically significant heterogeneity in preferences across respondents. Almost all parameters are statistically significant from zero and consistent with prior expectations, suggesting that respondents understood the 
DCE task and made choices in a manner consistent with the assumptions of random utility theory. The MNL model was presented in supplementary table 1 and presents consistent results.

\section{Supplementary table 1: Multinomial logit model}

\begin{tabular}{|c|c|c|}
\hline & Adult Females & Adult Males \\
\hline Products: Vaginal ring & $-1.13(0.07)^{* * *}$ & - \\
\hline Implant & $-0.01(0.06)$ & $-0.59(0.06)^{* * *}$ \\
\hline Injectable & $0.19(0.06)^{* * *}$ & $-0.37(0.06)^{* * *}$ \\
\hline Circumcision & - & $-0.21(0.04)^{* * *}$ \\
\hline Oral PrEP (base) & & \\
\hline Protection: HIV protection (100\%) & $3.22(0.16)^{* * *}$ & $3.13(0.12)^{* * *}$ \\
\hline Pregnancy prevention & $0.34(0.05)^{* * *}$ & $0.28(0.04)^{* * *}$ \\
\hline STI protection & $0.09(0.05)^{*}$ & $0.19(0.04)^{* * *}$ \\
\hline Ability to use in secret & $0.12(0.05)^{* * *}$ & $0.09(0.04)^{* *}$ \\
\hline Waiting time & $0.04(0.03)$ & $0.09(0.02)^{* * *}$ \\
\hline Opt-out & $3.03(0.14)^{* * *}$ & $0.7(0.14)^{* * *}$ \\
\hline Male condom & $0.84(0.11)^{* * *}$ & $-0.37(0.2)^{*}$ \\
\hline
\end{tabular}

Among adult women, the intravaginal ring is the least preferred product modality. Oral PrEP, an injectable and an implant valued similarly. Among adult men, oral PrEP is preferred over any other product or method, with an implant indicated to be the least preferred option. Men prefer new products to the male condom, whereas women were more likely to choose condom use over new products.

In both groups, HIV protection was the most influential determinant of choice suggesting that efficacy of products would be critical in driving demand. Respondents also showed 
strong preferences for MPTs. Pregnancy and STI protection were significantly valued by both men and women, though pregnancy protection was valued three-times higher than STI protection among women and almost two times higher among men. Although not influential to the choices of women, a degree of waiting time was valued amongst men.

Men were more likely to choose a new product than women, as shown by significant optout parameters with different signs. Finally, whilst adult women value the use of male condoms, the opposite is true amongst adult males, and the significantly negative coefficient for male condom indicates that men who currently use condoms are likely to move to new products.

Table 3: Mixed multinomial logit model

\begin{tabular}{|c|c|c|c|c|}
\hline & \multicolumn{2}{|r|}{ Males } & \multicolumn{2}{|c|}{ Females } \\
\hline & Mean & SD & Mean & SD \\
\hline \multicolumn{5}{|l|}{ Products: Oral PrEP (base) } \\
\hline \multirow[t]{2}{*}{ Implant } & $-1.260 * * *$ & $2.655^{* * *}$ & -0.125 & $3.105^{* * *}$ \\
\hline & $(0.189)$ & $(0.197)$ & $(0.205)$ & $(0.231)$ \\
\hline \multirow[t]{2}{*}{ Injectable } & $-1.084 * * *$ & $2.320 * * *$ & -0.223 & $3.326 * * *$ \\
\hline & $(0.167)$ & $(0.178)$ & $(0.195)$ & $(0.252)$ \\
\hline \multirow[t]{2}{*}{ Circumcision* } & $-0.821 * * *$ & $3.119 * * *$ & & \\
\hline & $(0.171)$ & $(0.216)$ & & \\
\hline \multirow[t]{2}{*}{ Vaginal ring +} & & & $-3.616 * * *$ & $3.772 * * *$ \\
\hline & & & $(0.345)$ & $(0.331)$ \\
\hline \multirow[t]{2}{*}{ Protection: HIV protection (100\%) } & $0.0742 * * *$ & $-0.0669 * * *$ & $0.0668 * * *$ & $-0.0541 * * *$ \\
\hline & $(0.00510)$ & $(0.00462)$ & $(0.00489)$ & $(0.00370)$ \\
\hline \multirow[t]{2}{*}{ Pregnancy prevention } & $0.578 * * *$ & $0.873 * * *$ & $0.710 * * *$ & $1.091 * * *$ \\
\hline & $(0.0820)$ & $(0.0967)$ & $(0.109)$ & $(0.124)$ \\
\hline \multirow[t]{2}{*}{ STI protection } & $0.302 * * *$ & $-0.500 * * *$ & 0.0792 & $-0.496 * * *$ \\
\hline & $(0.0728)$ & $(0.129)$ & $(0.0914)$ & $(0.130)$ \\
\hline
\end{tabular}




\begin{tabular}{lcccc}
\hline Ability to use in secret & $0.191^{* * *}$ & 0.158 & 0.131 & $-0.310 * *$ \\
\hline & $(0.0644)$ & $(0.168)$ & $(0.0843)$ & $(0.124)$ \\
\hline Waiting time & $0.0997 * * *$ & -0.00398 & 0.0498 & $-0.163^{*}$ \\
\hline & $(0.0386)$ & $(0.0700)$ & $(0.0518)$ & $(0.0834)$ \\
\hline Opt-out & $-2.361 * * *$ & $-3.076 * * *$ & $3.037 * * *$ & $9.543 * * *$ \\
\hline Male condom & $(0.528)$ & $(0.499)$ & $(0.425)$ & $(0.630)$ \\
\hline & 0.173 & 0.439 & $11.17 * * *$ & $4.082 * * *$ \\
\hline Number of choices & $(0.534)$ & $(0.586)$ & $(0.862)$ & $(0.392)$ \\
\hline
\end{tabular}

* For men only + For females only. Coefficients shown with standard errors in parentheses.

$* * *, * *, *==>$ Significance at $1 \%, 5 \%, 10 \%$ level. 1,000 Halton draws.

\section{Uptake predictions}

Figure 2 shows uptake predictions from the MNL model for male and female groups, with data weighted to consider migration from condoms, using reported data of condom use at last sex; $12 \%$ among women, and $26 \%$ among men. These results are subject to the IIA assumption required in the MNL model, and do not give a guide to absolute uptake, but can provide a useful indication of uptake patterns. Among women, there were comparable levels of demand for oral PrEP, injectable, and implant products, however uptake of an intravaginal ring was predicted to be substantively lower. Condom use was not predicted to be substantially affected by the introduction of new products amongst women, although we predicted condom use to decrease among men by around one third. 
Figure 2: Multinomial logit uptake predictions by sex

Predicted uptake by type and scenario of prevention: Female group

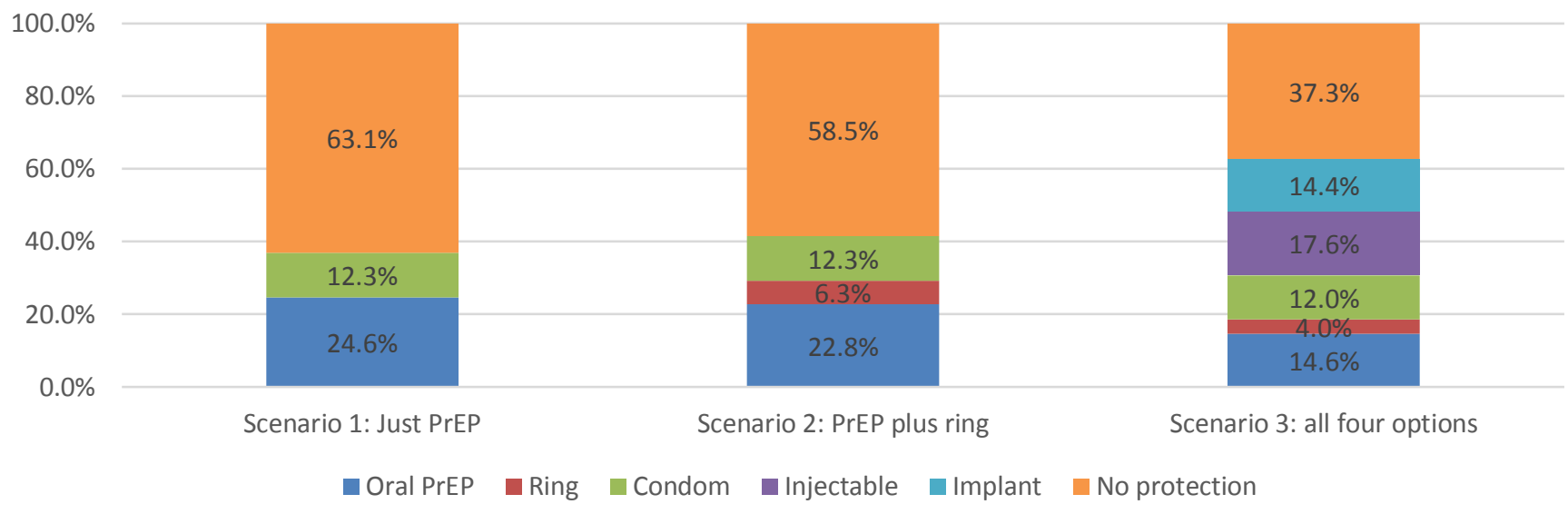

Predicted uptake by type and scenario of prevention: Male group

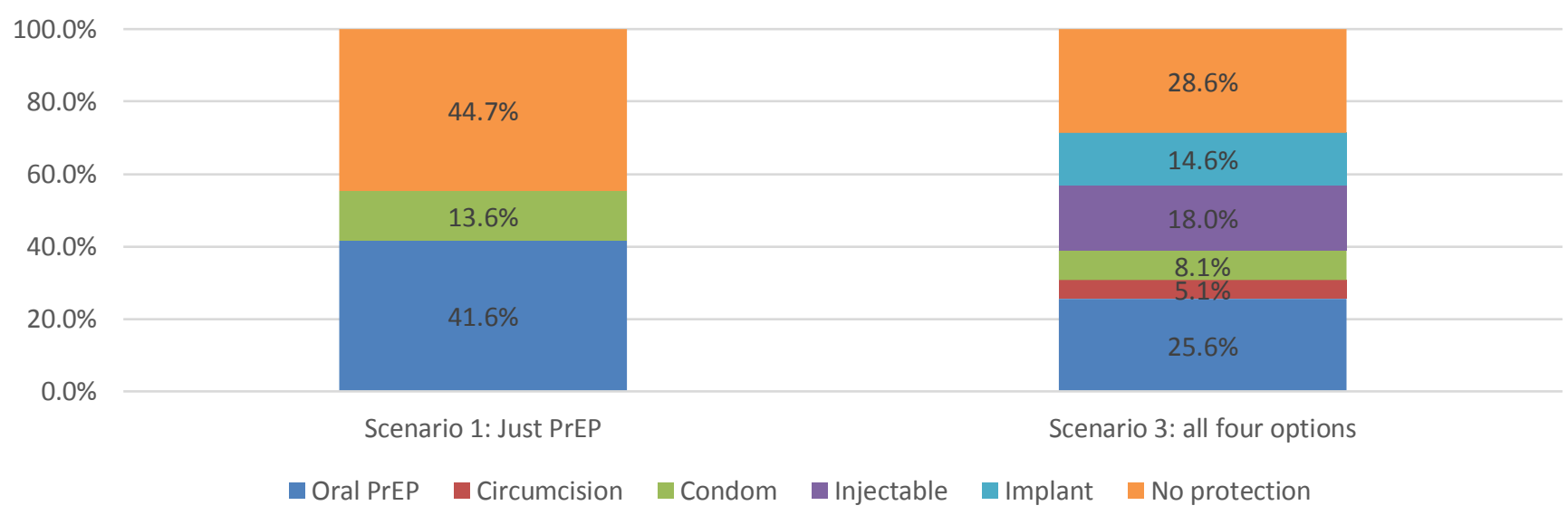

\section{Preference heterogeneity}

Preference heterogeneity was explored through latent class models shown in table 4, run separately and without sample weighting for male and female samples. Three latent classes were used for each model. Men in class 1 demonstrated very strong preferences for HIV protection and no preference for STI or pregnancy protection. Men in this class were likely to avoid choosing new products at all and particularly dislike the implant and injectable products. Relative to class 3 , men in this group were more likely to be older and more likely to have ever used drugs. 
The characteristics of men in classes 2 and 3 were statistically similar, and although men in these classes would preferred products offering multipurpose protection from HIV, STIs, and pregnancy, other preference differed. For example, men in class 3 found the injectable product, and circumcision attractive whilst men in class 2 did not. Men in class 3 also found the male condom an unappealing product and were likely to choose unprotected sex more than men in class 2. Finally, the preference for longer waiting times is only weakly statistically significant among one male group in this model, in contrast to the MMNL findings of a preference for waiting longer.

Female preferences were variable, and were impacted by structural factors including exposure to intimate partner violence (IPV). There was heterogeneity in preferences for multipurpose prevention products. Whereas women in class 1 strongly valued a contraceptive and HIV protective product, women in classes 2 and 3 valued HIV and STI protection only. We identified a comparatively more vulnerable class of women who were more likely to have experienced IPV in the previous year and were less likely to make decisions around their health and finances (class 2 relative to class 3 ). Class 2 women had strong, positive preferences for the longer-lasting products of the implant, injectable, and vaginal ring compared to oral PrEP, and significantly valued secrecy of use. By contrast, women likely to be in class 1 strongly preferred the implant over all other products and found contraceptive protection attractive. Class 1 women were also more likely to be older and with prior IPV. Finally, the largest and least vulnerable class identified was class 3 in which 53\% strongly preferred oral PrEP over any other product.

Table 4: Latent class model

\section{Class membership}

probability

Products: Oral PrEP (base)

\begin{tabular}{|l|l|l|l|l|l|}
\hline Males & & \multicolumn{2}{l|}{ Females } \\
Class 1 & \multicolumn{2}{l}{ Class 2 } & \multicolumn{2}{l|}{ Class 3 } & \multicolumn{2}{l|}{ Class 1 } & \multicolumn{2}{l|}{ Class 2 } & \multicolumn{1}{l|}{ Class 3 } \\
\hline $36 \%$ & $40 \%$ & $25 \%$ & $26 \%$ & $21 \%$ & $53 \%$ \\
\hline & & & & &
\end{tabular}




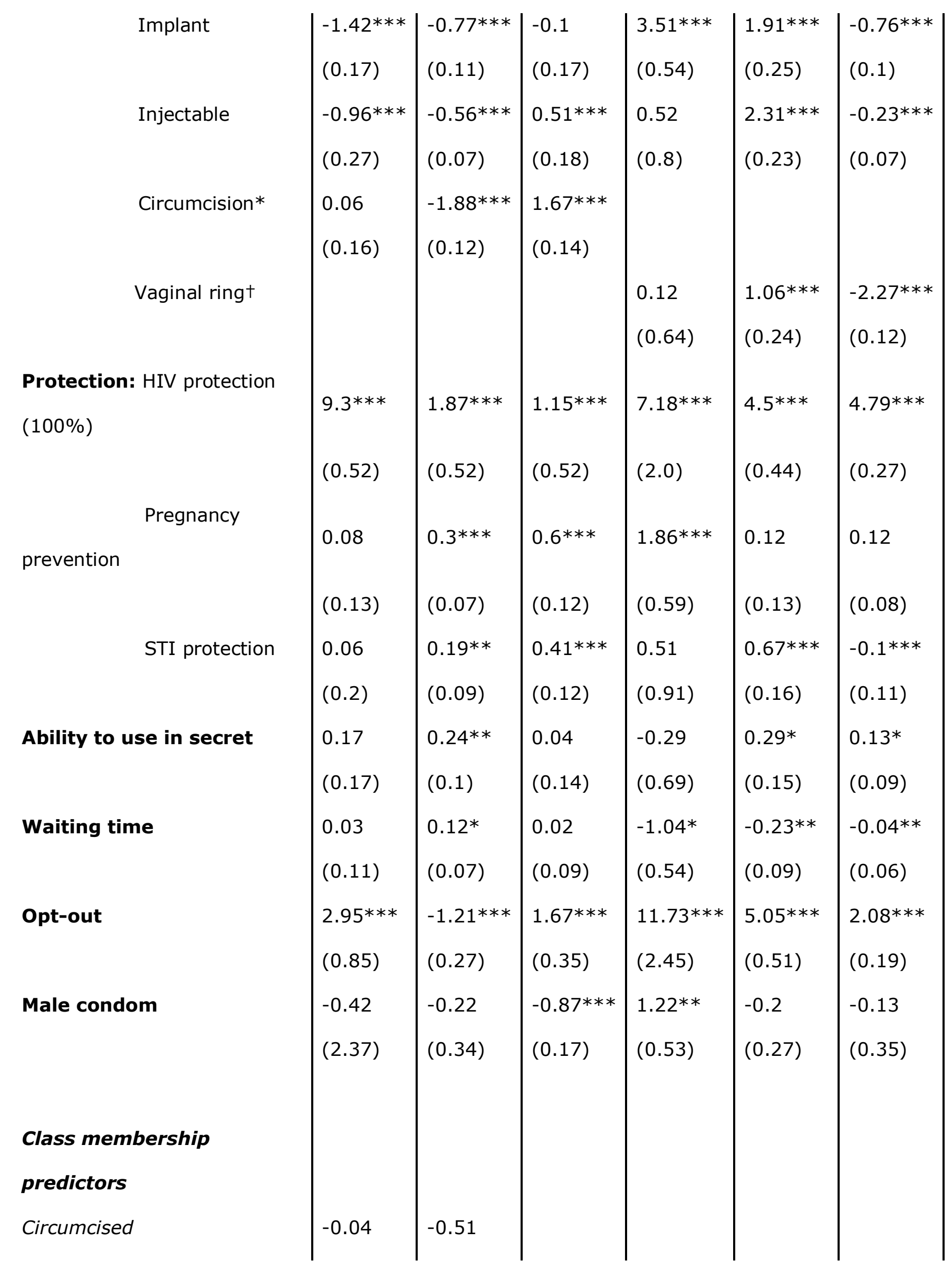




\begin{tabular}{l|l|l|l|l|l|} 
Makes no household decisions & -0.18 & -0.04 & 0.32 & $-1.34 * * *$ \\
No household hunger & -0.32 & -0.22 & -0.17 & 0.05 \\
Ever drink alcohol & -0.21 & -0.19 & 0.42 & 0.57 \\
Ever used drugs & $1.65 * *$ & 1.01 & -0.14 & -0.97 \\
Age & $0.03 *$ & 0.02 & $0.04 * * *$ & 0.0 \\
Experienced IPV in last year & & & $1.41 * * *$ & $1.59 * * *$
\end{tabular}




\section{DISCUSSION}

Fishing communities in Uganda are an important population for HIV prevention given high rates of transmission. This is the first study, to our knowledge, that elicits the preferences of members of this sub-population to assess potential demand for a range of new ARV-based HIV prevention products for PrEP. We found that products were generally attractive and acceptable to potential users, but preferences for specific product modalities and attributes were heterogeneous.

For example, the largest group identified in a latent class analysis found oral PrEP the most attractive product to women. However, more vulnerable women (i.e. younger women, women using alcohol, women who had experienced intimate partner violence (IPV) in the previous year and women who do not make household decisions) significantly valued other products such as implants and injectable PrEP over oral PrEP. The attractiveness of oral PrEP among males could lead to relatively high HIV protection and even higher protection if oral PrEP, condom use and male circumcision are considered. These results indicate that a one-size-fits-all approach to HIV prevention programming (for example, only introducing one product) will not maximize benefits, and may lead to misallocation of scarce resources, particularly in our fishing communities

Correlations between heterogeneity in the HIV risk in fishing communities and their preferences for new products need to be accounted for so that effective, attractive products get into the hands of those who will use them well. Evidence suggests that the HIV prevention field can learn from successes and failures in contraceptive programming (54), in particular the need to focus on creating an attractive product mix versus provision of single technology products.

Strong evidence for a bidirectional relationship between IPV and HIV/AIDS has emerged from prospective cohort studies $(55,56)$. Fishing communities face several structural 
barriers to HIV including IPV $(31,57)$. Our study further showed that IPV might inform decision making on preferences for HIV prevention methods. To be effective, HIV combination prevention interventions for fishing communities must be implemented using approaches that build individual agency, self-efficacy and skills that strengthen community cohesion to improve uptake of prevention products. Some projects already do this, such as (Safe Homes And Respect for Everyone) SHARE, a combined IPV and HIV prevention intervention which resulted in a significant decline in physical and sexual violence and HIV incidence, in a general population in rural Uganda (58).

Previous studies have highlighted some of the barriers to PrEP use including HIV-related stigma, limited knowledge of PrEP, and inadequate access to PrEP (59-61). In addition, controversies over global inequalities in access to ART including PrEP persist. For instance coverage of ART for those eligible is still quite low, and expanding PrEP services may be similarly suboptimal (62). However, the results of this study suggest that, if supply-side barriers can be overcome, there may be substantial demand for new prevention options from the fishing communities as a high-risk group.

Among women, condom use is not predicted to be substantially affected by the introduction of new products, suggesting that risk compensation (63)-where people adjust their behavior in response to the perceived level of risk may not occur. However, we predict a one-third reduction in condom use among men because men prefer new products to the male condom. Men's potential to stop using condoms in preference to PrEP has implications for HIV and other sexually transmitted infections and contraception. More research is needed to understand the contexts in which risk compensation occurs to a greater or lesser extent, and to understand how this might affect product impact.

Our results also highlight that MPTs could potentially fill significant unmet sexual and reproductive health needs in fishing communities with high HIV incidence of curable STI 
(4)(64) and inadequate contraception provision. MPTs increase efficiencies in delivery and access to products. Furthermore, increased demand for MPTs may indirectly improve contraception and STI control coverage (65). MPTs have been predicted to be costeffective in high-risk female sex workers and young women in South Africa (66); more research is needed on the cost-effectiveness of MPTs in different contexts.

\section{Study strengths and limitations}

A major strength of our study was that the DCE approach allows us to explore fishing communities' demand and preferences for both old, new and upcoming HIV prevention techniques. The study was conducted prior to the roll-out of oral PrEP, and findings can be used to inform strategic implementation of oral PrEP and other new HIV prevention products that may be developed. We provided respondents with actual products instead of visual representations of the product, which aided individual evaluation of the products and attributes, making our results more valid than if all choices had been presented hypothetically. Nevertheless, the imperfect external validity of DCEs imply that results may differ from revealed preferences. Uptake predictions based on hypothetical data analysed with an MNL model may differ from those chosen in reality. We selected respondents using stratified random sampling from two urban and two rural communities. Thus, our findings may be generalizable to similar fishing communities elsewhere in Uganda and other parts of East Africa.

The actual cost of the prevention methods might influence the real-world choice of prevention methods for both the provider and the end user. However, we did not explore real or probable product cost because we could not ascertain whether new HIV prevention products would be available free or at a subsidized cost by the government of Uganda. Currently, the available prevention products are highly subsidized by government and often offered free of charge in public health facilities although condoms are also sold in private facilities at less than 50 cents. 
All information analyzed in this work was based on self-reported behavior, which may be subject to social desirability bias, especially so for this study population that receives frequent safer HIV prevention messaging, potentially leading to over-reporting of condom use and prevention product use. We used the multinomial logit model to predict uptake which requires the restrictive independence of irrelevant alternatives assumption to hold. Therefore our results should be used as a guide to the pattern of demand. We could not find a satisfactory explanation for why a degree of waiting time was valued amongst some men, though the latent class analysis suggests that this is not the case once heterogeneity has been considered.

\section{Recommendations and conclusion}

Oral PrEP is acceptable among fishing communities. Both men and women had a strong preference for oral PrEP although preferences for products and product attributes were heterogeneous. Future work should explore actual utility of MPTs among fisherfolk in Uganda as part of a combination HIV prevention package.

\section{References}

1. UNAIDS. Fact sheet: Global HIV statistics 2017 [Available from: http://www.unaids.org/sites/default/files/media asset/UNAIDS FactSheet en.pdf.

2. Seeley J, Nakiyingi-Miiro J, Kamali A, Mpendo J, Asiki G, Abaasa A, et al. High HIV incidence and socio-behavioral risk patterns in fishing communities on the shores of Lake Victoria, Uganda. Sexually transmitted diseases. 2012;39(6):433-9.

3. Kiwanuka N, Ssetaala A, Mpendo J, Wambuzi M, Nanvubya A, Sigirenda S, et al. High HIV-1 prevalence, risk behaviours, and willingness to participate in HIV vaccine trials in fishing communities on Lake Victoria, Uganda. Journal of the International AIDS Society. $2013 ; 16(1)$. 
4. Kiwanuka N, Ssetaala A, Nalutaaya A, Mpendo J, Wambuzi M, Nanvubya A, et al. High incidence of HIV-1 infection in a general population of fishing communities around Lake Victoria, Uganda. PLoS ONE. 2014;9(5):e94932.

5. Ministry of Health. National HIV Prevention Strategy 2011 - 2015 [Available from: http://www.aidsuganda.org/images/documents/NPS.pdf.

6. Kamali A, Price $M$, Lakhi S, Karita E, Inambao M, Sanders E, et al. Creating an African HIV Clinical Research and Prevention Trials Network: HIV Prevalence, Incidence and Transmission. PloS one. 2014;10(1):e0116100-e.

7. Asiki G, Baisley K, Kamali A, Kaleebu P, Seeley J, Newton R. A prospective study of trends in consumption of cigarettes and alcohol among adults in a rural Ugandan population cohort, 1994-2011. Tropical medicine \& international health. 2015;20(4):52736.

8. Opio A, Muyonga M, Mulumba N. HIV Infection in Fishing Communities of Lake Victoria Basin of Uganda-A Cross-Sectional Sero-Behavioral Survey. PloS one. 2013;8(8):e70770.

9. Allison EH, Seeley J. Another group at high risk for HIV. Science. 2004a;305,(1104.).

10. Kissling E, Allison EH, Seeley JA, Russell S, Bachmann M, Musgrave SD, et al. Fisherfolk are among groups most at risk of HIV: cross-country analysis of prevalence and numbers infected. AIDS. 2005;19(17):1939-46.

11. Kiwanuka N, Ssetaala A, Mpendo J, Wambuzi M, Nanvubya A, Sigirenda S, et al. High HIV-1 prevalence, risk behaviours, and willingness to participate in HIV vaccine trials in fishing communities on Lake Victoria, Uganda. J Int AIDS Soc. 2013;16.

12. Sileo K, Kintu M, Kiene S. History of sexual abuse, depression, and alcohol use as risk factors for HIV infection in high HIV prevalence fishing communities in rural Uganda. Ann Global Health. 2015;81.

13. Tumwesigye NM, Atuyambe L, Wanyenze RK, Kibira SP, Li Q, Wabwire-Mangen F, et al. Alcohol consumption and risky sexual behaviour in the fishing communities: evidence from two fish landing sites on Lake Victoria in Uganda. BMC Public Health. 2012;12(1):1. 
14. Kibengo FM, Ruzagira E, Katende D, Bwanika AN, Bahemuka U, Haberer JE, et al. Safety, adherence and acceptability of intermittent tenofovir/emtricitabine as HIV preexposure prophylaxis (PrEP) among HIV-uninfected Ugandan volunteers living in HIVserodiscordant relationships: a randomized, clinical trial. PloS one. 2013;8(9):e74314.

15. Kwena ZA, Camlin CS, Shisanya CA, Mwanzo I, Bukusi EA. Short-term mobility and the risk of HIV infection among married couples in the fishing communities along Lake Victoria, Kenya. PloS one. 2013;8(1):e54523.

16. Nunan F. Mobility and fisherfolk livelihoods on Lake Victoria: Implications for vulnerability and risk. Geoforum. 2010;41(5):776-85.

17. Nunan F, Luomba J, Lwenya C, Yongo E, Odongkara K, Ntambi B. Finding space for participation: fisherfolk mobility and co-management of Lake Victoria fisheries. Environmental management. 2012;50(2):204-16.

18. Uganda HIV/AIDS knowledge management communications capacity. Most at risk populations-fishing communities and HIV in Uganda: Synthesis of information and evidence to inform the response. 2014.

19. Buchbinder SP, Glidden DV, Liu AY, McMahan V, Guanira JV, Mayer KH, et al. HIV pre-exposure prophylaxis in men who have sex with men and transgender women: a secondary analysis of a phase 3 randomised controlled efficacy trial. The Lancet Infectious Diseases. 2014;14(6):468-75.

20. Baeten JM, Donnell D, Ndase P, Mugo NR, Campbell JD, Wangisi J, et al. Antiretroviral prophylaxis for HIV prevention in heterosexual men and women. New England Journal of Medicine. 2012;367(5):399-410.

21. Thigpen MC, Kebaabetswe PM, Paxton LA, Smith DK, Rose CE, Segolodi TM, et al. Antiretroviral preexposure prophylaxis for heterosexual HIV transmission in Botswana. New England Journal of Medicine. 2012;367(5):423-34.

22. Karim QA, Karim SSA, Frohlich JA, Grobler AC, Baxter C, Mansoor LE, et al. Effectiveness and safety of tenofovir gel, an antiretroviral microbicide, for the prevention of HIV infection in women. Science. 2010;329(5996):1168-74. 
23. Grant RM, Lama JR, Anderson PL, McMahan V, Liu AY, Vargas L, et al. Preexposure chemoprophylaxis for HIV prevention in men who have sex with men. New England Journal of Medicine. 2010;363(27):2587-99.

24. Choopanya K, Martin M, Suntharasamai P, Sangkum U, Mock PA, Leethochawalit M, et al. Antiretroviral prophylaxis for HIV infection in injecting drug users in Bangkok, Thailand (the Bangkok Tenofovir Study): a randomised, double-blind, placebo-controlled phase 3 trial. The Lancet. 2013;381(9883):2083-90.

25. Anderson PL, Glidden DV, Liu A, Buchbinder S, Lama JR, Guanira JV, et al. Emtricitabine-tenofovir concentrations and pre-exposure prophylaxis efficacy in men who have sex with men. Science Translational Medicine. 2012;4(151):151ra25-ra25.

26. McCormack S, editor Pragmatic Open-Label Randomised Trial of Preexposure Prophylaxis: The PROUD Study. Conference on Retroviruses and Opportunistic Infections (CROI), Seattle, USA, abstract 22LB2015.

27. Ministry of Health Uganda. Consolidated guidelines for prevention and treatment of HIV in Uganda 2016 [Available from: https://aidsfree.usaid.gov/sites/default/files/uganda_hiv_gl 2016.pdf.

28. Baeten JM, Palanee-Phillips T, Brown ER, Schwartz K, Soto-Torres LE, Govender V, et al. Use of a vaginal ring containing dapivirine for HIV-1 prevention in women. New England Journal of Medicine. 2016;375(22):2121-32.

29. Nel A, van Niekerk N, Kapiga S, Bekker L-G, Gama C, Gill K, et al. Safety and efficacy of a dapivirine vaginal ring for HIV prevention in women. New England Journal of Medicine. 2016;375(22):2133-43.

30. Marrazzo JM, Ramjee G, Richardson BA, Gomez K, Mgodi N, Nair G, et al. Tenofovirbased preexposure prophylaxis for HIV infection among African women. New England Journal of Medicine. 2015;372(6):509-18.

31. HIV Prevention Trials Network. HPTN: A Phase 3 Double Blind Safety and Efficacy Study of Long-Acting Injectable Cabotegravir Compared to Daily Oral TDF/FTC for PreExposure Prophylaxis in HIV-Uninfected Women 2018 [Available from: https://www.hptn.org/research/studies/hptn084. 
32. Gray RH, Kigozi G, Serwadda D, Makumbi F, Watya S, Nalugoda F, et al. Male circumcision for HIV prevention in men in Rakai, Uganda: a randomised trial. The Lancet. $2007 ; 369(9562): 657-66$.

33. Bailey RC, Moses S, Parker CB, Agot K, Maclean I, Krieger JN, et al. Male circumcision for HIV prevention in young men in Kisumu, Kenya: a randomised controlled trial. The lancet. 2007;369(9562):643-56.

34. Centre for Disease Control. Pre-exposure Prophylaxis for the Prevention of HIV Infection in the United States 2014 [Available from: http://www.cdc.gov/hiv/pdf/prepguidelines2014.pdf.

35. World Health Organization. Consolidated guidelines on general HIV care and the use of antiretroviral drugs for treating and preventing HIV infection: recommendations for a public health approach.

2013

[Available

from:

(http://www.who.int/iris/bitstream/10665/85321/1/9789241505727 eng.pdf.

36. Baeten J, Celum C, editors. Antiretroviral pre-exposure prophylaxis for HIV-1 prevention among heterosexual African men and women: the Partners PrEP Study. 6th IAS Conference on HIV Pathogenesis, treatment and Prevention; 2011.

37. Mugwanya K, Donnell D, Celum C, Mugo N, Thomas K, Ngure K, et al. O11. 2 Sexual Behaviour of Heterosexual Men and Women Receiving Antiretroviral Pre-Exposure Prophylaxis For HIV Prevention: Post-Unblinding Analysis of the Partners PrEP Study. Sexually transmitted infections. 2013;89(Suppl 1):A46-A.

38. Ndase P, Celum C, Campbell J, Bukusi E, Kiarie J, Katabira E, et al. Successful Discontinuation of the Placebo Arm and Provision of an Effective HIV Prevention Product After a Positive Interim Efficacy Result: The Partners PrEP Study Experience. JAIDS Journal of Acquired Immune Deficiency Syndromes. 2014;66(2):206-12.

39. Mensch BS, van der Straten A, Katzen LL. Acceptability in microbicide and PrEP trials: current status and a reconceptualization. Current Opinion in HIV and AIDS. 2012;7(6):534. 
40. Francis JM, Grosskurth H, Changalucha J, Kapiga SH, Weiss HA. Systematic review and meta-analysis: prevalence of alcohol use among young people in eastern Africa. Tropical Medicine \& International Health. 2014;19(4):476-88.

41. AVAC Global advocacy for HIV prevention. Ongoing and Planned PrEP Trials and Demonstration Projects 2013 [Available from: http://www.prepwatch.org/wpcontent/uploads/2014/01/PrEP-Trials-and-Demo-Projects-December-2013.pdf.

42. Seeley J, Tumwekwase G, Grosskurth H. Fishing for a living but catching HIV: AIDS and changing patterns of the organization of work in fisheries in Uganda. Anthropology of Work Review. 2009;30(2):66-76.

43. Uganda Ministry of Agricultue, Animal Industry and Fisheries.(n.d). Departments: Fisheries Resources. [Available from: http://www.agriculture.go.ug/index-pagedepartments-id-87.htm.

44. Boffito M, Jackson A, Owen A, Becker S. New approaches to antiretroviral drug delivery: challenges and opportunities associated with the use of long-acting injectable agents. Drugs. 2014;74(1):7-13.

45. Kuteesa MO, Weiss HA, Abaas A, Nash S, Nsubuga RN, Newton R, et al. Feasibility of conducting HIV combination prevention interventions in fishing communities in Uganda: a cluster randomised trial. . In press 2018.

46. ChoiceMetrics. Ngene version 1.1.2. Sydney, Australia2012.

47. Hensher D, Rose J, Greene W. Applied Choice Analysis: Second Edition. Cambridge: Cambridge University Press; 2015.

48. de Bekker-Grob EW, Ryan M, Gerard K. Discrete choice experiments in health economics: a review of the literature. Health Econ. 2012;21(2):145-72.

49. Hess S, Bierlaire M, Polak JW. Estimation of value of travel-time savings using mixed logit models. Transportation Research Part A: Policy and Practice. 2005;39(23):221-36.

50. Fonner VA, Dalglish SL, Kennedy CE, Baggaley R, O'Reilly K R, Koechlin FM, et al. Effectiveness and safety of oral HIV pre-exposure prophylaxis (PrEP) for all populations: A systematic review and meta-analysis. Aids. 2016. 
51. Baeten JM, Palanee-Phillips T, Brown ER, Schwartz K, Soto-Torres LE, Govender V, et al. Use of a vaginal ring containing dapivirine for HIV-1 prevention in women. New England Journal of Medicine. 2016.

52. Davis KR, Weller SC. The effectiveness of condoms in reducing heterosexual transmission of HIV. Family planning perspectives. 1999;31(6):272-9.

53. Gray RH, Kigozi G, Serwadda D, Makumbi F, Watya S, Nalugoda F, et al. Male circumcision for HIV prevention in men in Rakai, Uganda: a randomised trial. Lancet. $2007 ; 369(9562): 657-66$.

54. Delany-Moretlwe S, Mullick S, Eakle R, Rees H. Planning for HIV preexposure prophylaxis introduction: lessons learned from contraception. Current Opinion in HIV and AIDS. $2016 ; 11(1): 87-93$.

55. Kouyoumdjian FG, Findlay N, Schwandt M, Calzavara LM. A systematic review of the relationships between intimate partner violence and HIV/AIDS. PLoS One. 2013;8(11):e81044.

56. Wagman JA, Gray RH, Campbell JC, Thoma M, Ndyanabo A, Ssekasanvu J, et al. Effectiveness of an integrated intimate partner violence and HIV prevention intervention in Rakai, Uganda: analysis of an intervention in an existing cluster randomised cohort. The Lancet Global Health. 2015;3(1):e23-e33.

57. Sileo KM, Kintu M, Kiene SM. The intersection of intimate partner violence and HIV risk among women engaging in transactional sex in Ugandan fishing villages. AIDS care. $2018 ; 30(4): 444-52$.

58. Wagman JA, King EJ, Namatovu F, Kiwanuka D, Kairania R, Semanda JB, et al. Combined intimate partner violence and HIV/AIDS prevention in rural Uganda: design of the SHARE intervention strategy. Health care for women international. 2016;37(3):36487.

59. Idoko J, Ukpong MO, Dadem NY, Kolawole GO, Anenih J, Alhassan E. Why Should I Take Drugs for your Infection: Outcomes of Formative Research on Use of PrEP in Nigeria. AIDS research and human retroviruses. 2014;30(S1):A80-A1. 
60. van der Straten A, Stadler J, Luecke E, Laborde N, Hartmann M, Montgomery ET, et al. Perspectives on use of oral and vaginal antiretrovirals for HIV prevention: the VOICEC qualitative study in Johannesburg, South Africa. Journal of the International AIDS Society. 2014;17(3Suppl 2).

61. Joint United Nations Programme on HIV/AIDS (UNAIDS). The Gap Report. UNAIDS, Geneva, Switzerland 2014 [Available from: http://www.unaids.org/en/resources/documents/2014/20140716 UNAIDSgap report.

62. Belluz J. The Truvada wars. British Medical Journal. 2014;348:g3811.

63. Graham J. Target Risk: Dealing with the Danger of Death, Disease and Damage in Everyday Decisions. Injury Prevention. 1998;4(2):162-3.

64. Mbonye M, Nalukenge W, Nakamanya S, Nalusiba B, King R, Vandepitte J, et al. Gender inequity in the lives of women involved in sex work in Kampala, Uganda. Journal of the International AIDS Society. 2012;15 (no pagination)(633).

65. Fernández-Romero JA, Deal C, Herold BC, Schiller J, Patton D, Zydowsky T, et al. Multipurpose prevention technologies: the future of HIV and STI protection. Trends in microbiology. 2015;23(7):429-36.

66. Quaife M, Terris-Prestholt F, Eakle R, Cabrera Escobar MA, Kilbourne-Brook M, Mvundura M, et al. The cost-effectiveness of multi-purpose HIV and pregnancy prevention technologies in South Africa. J Int AIDS Soc. 2018;21(3). 